\title{
Evaluation of the Efficacy of Sapta Winsati Guggulu in the Management of Shushkarsha: A Comparative Clinical Study
}

\author{
Fernando BPA ${ }^{1}$, Hettiarachchi GTK ${ }^{2}$, Kumara GUA ${ }^{3}$, Pushpakumara AAJ ${ }^{4}$ \\ ${ }^{1}$ Community Medical Officer, Department of Ayurveda, North Province, Sri Lanka. \\ ${ }^{2}$ Medical Officer, Department of Ayurveda, North Province, Sri Lanka. \\ ${ }^{3}$ Lecturer (Probationary), University College, University of Vocational Technology, Kuliyapitiya, Sri Lanka. \\ ${ }^{4}$ Senior Lecturer, Department of Shalya Shalakya, Faculty of Indigenous Medical Sciences, Gampaha \\ Wickramarachchi University of Indigenous Medicine, Sri Lanka.
}

Corresponding Author: G.U.A. Kumara

\begin{abstract}
Introduction: Hemorrhoids, also called piles, co-related with Arsha in Ayurveda, are swollen veins in the anus and the lower rectum, similar to varicose veins. Hemorrhoids can develop inside the rectum known as internal hemorrhoids or under the skin around the anus known as external hemorrhoids. Worldwide, the prevalence of symptomatic hemorrhoids is estimated at $4.4 \%$ in the general population.

Objectives: This is a clinical study was conducted to evaluate the efficacy of the Sapta Winshati Guggulu in the management of Shushkarsha.

Methodology: 40 patients diagnosed with Shushkarsha were randomly selected to this study and they were randomly divided into two groups and was named as the Group-A (Tested group) and the Group-B (Control group). All the patients (both A and B groups) were treated by Abhayarishta, Chirabilwa Kwatha and Sukumara Churna. Only Group-A (testing group) was additionally treated with Sapta Winshati Guggulu. Data collection: Subjective parameters such as pain and Objective parameters such as circumference of the pile and distance of the prolapse were collected.

Data analysis: All the subjective and objective parameters were entered by using reputed methods and were analyzed by using graphs and figures and SPSS Statistical Software.

Results: p-value and t-value of Group-A and Group-B were statistically significant. But, Significant level of Group-A was higher than Group-B.

Conclusion: According to the findings, finally it can be concluded that the Sapta Winshati Guggulu has remarkable effect in the management of the Shushkarsha.
\end{abstract}

Key Words: Hemorrhoids, Piles, Shushkarsha, Chirabilwa Kwatha, Sapta Winshati Guggulu

\section{INTRODUCTION}

Scope of the Work: Hemorrhoids are classified into two types, depending on their level in relation to anus. Those are internal hemorrhoids and external hemorrhoids. Internal hemorrhoids are further divided into four degrees depending on their symptoms produced. Grade I: The hemorrhoids do not prolapse, only bleeding from the rectum can be seen. Grade II: The hemorrhoids prolapse upon defecation, but spontaneously reduce and bleeding may be occur. Grade III: The hemorrhoids prolapse upon defecation, but reduce after manipulation. Grade IV: The hemorrhoids are prolapsed and remain prolapsed. (1) (2) (3) (4)

Ayurvedic scholars corelate Arsha with Hemorrhoids and Raktarsha and Shushkarsha are the main 
Fernando BPA et.al. Evaluation of the efficacy of sapta winsati guggulu in the management of shushkarsha: a comparative clinical study.

two types of them. (5) (6) (7) (8) Arsha are considered to be stubborn, whereas Ayurveda provides the best alternative management as it acts on the root cause of the disease. (9) (10) (11) Since there is no surgical intervention, hence there are no chances of complications such as infections and bleedings. Also these treatment modalities are cost-effective and affordable treatment for people of developing countries.

Worldwide, the prevalence of symptomatic hemorrhoids is estimated at $4.4 \%$ in the general population. Among people older than 45 years, $25 \%$ of people who develop hemorrhoids are female and $15 \%$ are men. Research has also shown there is a greater likelihood of men seeking treatment for their hemorrhoids than there is for women. ${ }^{(12)}$
Hence, in the present study, the efficacy of the Sapta Winshati Guggulu on Shushkarsha was studied clinically and results were presented statistically.

Aim and Objective: The aim of this study was to evaluate the efficacy of the Sapta Winshati Guggulu in the management of Shushkarsha.

Significance of the Study: In spite of many medicinal formulae in Ayurveda, there is no proper study has been done to prove their efficacy of most of Ayurvedic drugs. Therefore, some most effective formulae are slowly slipping away from the system. Sapta Winshati Guggulu is a herbo-mineral drug (Pill) which is mentioned in Ayurveda Pharmacopoeia and one of the above mentioned formulae. Hence, this study is highly valuable for Sri Lankan Ayurvedic Medical System.

\section{MATERIAL AND METHODS Preparation of the Drug: ${ }^{(13)(14)(15)}$}

\begin{tabular}{|c|c|c|c|}
\hline Sanskrit Name & Common Name & Latin Name & Part used \\
\hline Shunti & Ginger (dry) & Zingiber officinale & Rhizomes \\
\hline Maricha & Black Pepper & Piper nigrum & Seeds (Fruits) \\
\hline Pippali & Long Pepper & Piper longum & Seeds (Fruits) \\
\hline Haritaki & Myrobalan & Terminalia chebula & Fruits \\
\hline Vibhitaki & Bastard Myrobalan & Terminalia bellirica & Fruits \\
\hline Amalaki & Indian Gooseberry & Phyllanthus emblica & Fruits \\
\hline Musta & Nut Grass & Cyperus rotundus & Rhizomes \\
\hline Vidanga & False Black pepper & Embelia ribes & Seeds \\
\hline Guduchi & Heart Leaved Moonseed & Tinospora cordifolia & Stems \\
\hline Chitraka & Ceylon Leadwort & Plumbago zeylanica & Roots \\
\hline Shati & Java Galangal & Kaempferia galanga & Rhizomes \\
\hline Ela & True Cardamom & Elettaria cardamomum & Seeds (Fruits) \\
\hline Pippali & Long Pepper & Piper longum & Roots \\
\hline Hapusha & Common Juniper & Juniperus communis & Seeds \\
\hline Devadaru & Deodar cedar & Cedrus deodara & Stems (Heartwood) \\
\hline Dhanyaka & Coriander & Coriandrum sativum & Seeds (Fruits) \\
\hline Kushta & Costus root & Saussurea lappa & Roots \\
\hline Chavika & Large Betel Pepper & Piper chuvya & Roots \\
\hline Indravaruni & Bitter Apple & Citrullus colocynthis & Fruits \\
\hline Nisha & Turmeric & Curcuma longa & Rhizomes \\
\hline Darvi & Yellow vine & Coscinium fenestratum & Stems \\
\hline Gajapippali & Gajapippaly & Scindapsus officinalis & Seeds (Fruits) \\
\hline Ajamoda & Wild Celery / Ajowan & Trachyspermum involucratum & Seeds \\
\hline Vid Lavana & - & Ammonium chloride & - \\
\hline Sauwarchala & Black Salt & Combination of Sodium* & - \\
\hline Yawkshara & - & Potassium carbonate & - \\
\hline Swarajakshara & Washing Soda & Sodium bicarbonate & - \\
\hline Sahindawa & Rock Salt & Sodium chloride & - \\
\hline Gugul & Indian bdellium-tree & Commiphora wightii & Gum resin \\
\hline
\end{tabular}

\footnotetext{
* Black salts are made synthetically from a combination of sodium chloride, sodium sulfate, sodium bisulfate, and ferric sulfate. The salt is then mixed with charcoal and heated before the final product is ready.

** Triphala contains equal amounts of Haritaki, Vibhitaki and Amalaki. Triphala kwatha made from one part of herbs in sixteen parts of water, which is reduced to $1 / 4^{\text {th }}$ part of liquid after cooking on a low flame.
} 
All the ingredients and accessory ingredients were collected, cleaned and purified and then measured by using a measuring scale (equal amount of all the ingredients). Gugul was purified by using Triphala Kwatha**. Other ingredients were powdered, mixed with purified Gugul and were grinded by using a grinding stone. Finally, it was prepared $2 \mathrm{~g}$ pills, dried well and stored in a well cleaned-dried glass bottle.

Sample Selection: Forty (40) patients aged between 20 to 60 years, diagnosed as suffering from Shushkarsha were recruited for this study. All the Raktarsha patients were excluded from the study. The patients who are on any other internal or external medications for the last 7 days were also excluded from the study. After collecting details of the patients' history, the selected patients were thoroughly examined. The patients who gave written consent were included in the study. Severity of signs and symptoms were recorded before, during and after completion of treatment and also at the end of follow up period. Then after, patients were randomly divided into two groups such as Group-A (Tested group) and the Group-B (Control group).

\section{Method and Duration of Drug} Administration: All the patients (both A and B) were treated from $30 \mathrm{ml}$ of Chirabilwa Kwatha and $15 \mathrm{ml}$ of Abhayarishta after meals and twice a day. Only Group-A (testing group) was additionally treated with Sapta Winshati Guggulu (02 pills) after meals and twice a day. This treatment schedule was continued for the period of 28 days.
Dietary Regimen: The patients were advised to follow dietary restrictions according to the etiology of Shushkarsha. (16) (17) (18) (19) Apart from this, all the patients were restrained from taking other medications (internal and external), strong and spicy foods, coffee, tea, increased quantity of milk and milk products, condiments and other food items supposed to be possessing medicinal value during the study period and directed to take a regular and proper fibrous diet with adequate quantity of drinking water.

Follow-up: Patients were asked to come for clinical assessment once in seven (07) days for a period of one month after treatment procedure.

Data Collection: As a subjective parameter, the pain of the Shushkarsha was measured by using a specially prepared five point grading scale. The Grading scale was as follows:

$0=$ absent $=$ no pain in Arsha

$1=$ minimal $=$ occasionally feels pain in Arsha

$2=$ moderate $=$ intermittently feels pain in Arsha

$3=$ intense $=$ often feels pain in Arsha

$4=$ severe $=$ always feels pain in Arsha

As an objectives parameters, the circumference of the Arsha and Distance of the prolapse were measured by using a thread (converted to millimeters).

Statistical Analysis: Statistical analysis was carried out using the paired samples t-test of IBM SPSS Statistical Software Version 22. Results were tested at 0.05 confidence level.

\section{RESULTS}

Table 2: Stages of improvement (Grading system)

\begin{tabular}{|l|l|l|l|}
\hline Stage & Circumference of pile (\%) & Distance of prolapse (\%) & Score of pain \\
\hline Excellent $(\mathrm{E})$ & $80-100$ & $80-100$ & 0 \\
\hline Good $(\mathrm{G})$ & $60-79$ & $60-79$ & 0 \\
\hline Fair $(\mathrm{F})$ & $40-59$ & $40-59$ & 1 \\
\hline Poor $(\mathrm{P})$ & Below than 39 & Below than 39 & $2 \& 3$ \\
\hline
\end{tabular}

This table denotes that the Grading System for the stages of improvement of the signs and symptoms of Arsha for both A and B groups. 
Fernando BPA et.al. Evaluation of the efficacy of sapta winsati guggulu in the management of shushkarsha: a comparative clinical study.

Table 3: Stages of improvement

\begin{tabular}{|c|c|c|c|c|c|c|c|}
\hline \multicolumn{4}{|c|}{ Tested Group (Group-A) } & \multicolumn{4}{|c|}{ Control Group (Group-B) } \\
\hline $\begin{array}{l}\text { Patient } \\
\text { Number }\end{array}$ & $\begin{array}{l}\text { Circumference of } \\
\text { Pile (\%) }\end{array}$ & $\begin{array}{l}\text { Distance of } \\
\text { Prolapse (\%) }\end{array}$ & $\begin{array}{l}\text { Score of } \\
\text { Pain }\end{array}$ & $\begin{array}{l}\text { Patient } \\
\text { Number }\end{array}$ & $\begin{array}{l}\text { Circumference of } \\
\text { Pile }(\%)\end{array}$ & $\begin{array}{l}\text { Distance of } \\
\text { Prolapse }(\%)\end{array}$ & $\begin{array}{l}\text { Score of } \\
\text { Pain }\end{array}$ \\
\hline $\mathrm{T} 01$ & 70.0 & 66.7 & 0 & $\mathrm{C} 01$ & 9.4 & 12.5 & 2 \\
\hline T02 & 43.8 & 63.6 & 0 & $\mathrm{C} 02$ & -45.5 & 64.3 & 2 \\
\hline T03 & 75.0 & 6.7 & 0 & $\mathrm{C} 03$ & 66.7 & 40 & 3 \\
\hline T04 & 62.5 & 78.6 & 0 & $\mathrm{C} 04$ & 33.3 & 40 & 3 \\
\hline T05 & 92.6 & 88.9 & 0 & $\mathrm{C} 05$ & 8.3 & 40 & 3 \\
\hline T06 & 52.2 & 73.3 & 0 & $\mathrm{C} 06$ & 18.03 & 40 & 3 \\
\hline T07 & 44.2 & 68.8 & 1 & $\mathrm{C} 07$ & 15 & 14.3 & 3 \\
\hline T08 & 100 & 100 & 0 & $\mathrm{C} 08$ & 16.7 & 14.3 & 3 \\
\hline T09 & -61.6 & 28.6 & 0 & $\mathrm{C} 09$ & -15 & 0 & 3 \\
\hline T10 & 100 & 100 & 0 & $\mathrm{C} 10$ & 13.3 & 23.1 & 2 \\
\hline T11 & 61.3 & 60.0 & 0 & C11 & 2.8 & 13.3 & 3 \\
\hline $\mathrm{T} 12$ & 11.1 & 0 & 1 & C12 & 7.41 & 31.3 & 3 \\
\hline T13 & 2.8 & -42.9 & 0 & $\mathrm{C} 13$ & 25 & -63.6 & 3 \\
\hline T14 & 43.8 & \begin{tabular}{|l}
33.3 \\
\end{tabular} & 0 & C14 & $\begin{array}{l}4.8 \\
\end{array}$ & 0 & 2 \\
\hline $\mathrm{T} 15$ & 35.5 & -100 & 0 & $\mathrm{C} 15$ & 41.2 & 52.4 & 3 \\
\hline T16 & 66.7 & -140 & 0 & C16 & 20 & 50 & 3 \\
\hline T17 & 61.5 & 66.7 & 0 & C17 & 6.3 & 20 & 3 \\
\hline T18 & 16.7 & 54.6 & 0 & $\mathrm{C} 18$ & 2.13 & 70 & 3 \\
\hline T19 & 100 & 100 & 0 & C19 & 20 & 55.6 & 3 \\
\hline T20 & 100 & 100 & 0 & $\mathrm{C} 20$ & 20 & 44.4 & 3 \\
\hline
\end{tabular}

This table denotes that the overall improvement of both Tested Group (Group-A) and Control Group (Group-B). Further, improvement of the circumference of pile and the distance of prolapse were recorded as percentages and improvement of the pain was recorded as a score mentioned in above table 2.

Table 4: Analysis of p-values

\begin{tabular}{|l|l|l|l|l|l|l|l|}
\hline \multicolumn{7}{|c|}{ Table 4: Analysis of p-values } \\
\hline Tested Group (Group-A) & \multicolumn{5}{|c|}{ Control Group (Group-B) } \\
\hline 01 & 0.202 & 0.390 & 0.000 & 01 & 0.095 & 0.040 & 0.019 \\
\hline 02 & 0.015 & 0.307 & 0.000 & 02 & 0.067 & 0.006 & 0.018 \\
\hline 03 & 0.005 & 0.009 & 0.000 & 03 & 0.042 & 0.005 & 0.005 \\
\hline 04 & 0.000 & 0.001 & 0.000 & 04 & 0.007 & 0.041 & 0.004 \\
\hline
\end{tabular}

This table indicates that the calculated p-values of the symptoms of Arsha of both Group-A and B by week. According to that all the calculated p-values of both A and B groups are below than significant level (p-value < 0.05) after 28 days of treatment.

\section{DISCUSSION}

The Sapta Winsati Guggulu has 29 herbo-mineral ingredients. Among these most of ingredients have Shodhana, Lekhana, Arshoghna, Shothahara, Deepana, Shoolaprashamana and Virechana properties. ${ }^{(20)(21)(22)}$ All these properties are beneficial for the management of Arsha. Further, purified Gugul is the main ingredient of the drug and is half of the total weight. Although main action of the Gugul is pacifying the Vata dosha, prepared Guggulu gas Tridosha prashamana action.
In addition to, this drug has Vedanasthapaka (analgesic), Balya (tonic) and etc. qualities.

There was not any previous research for Sapta Winshati Guggulu, but there are so many researches for individual ingredients of this drug. Those researches were proven that these all ingredients are highly significant in the management of Arsha. ${ }^{(23)}$ (24) (25)

\section{CONCLUSION}

Statistical data shows that both treatment regimens are clinically significant as a treatment for Shushkarsha. But, after analyzing all the findings in scientifically, it can be concluded that the Sapta Winshati Guggulu has remarkable effect in the management of the Shushkarsha.

\section{ACKNOWLEDGEMENT}

Its pleasure to take this opportunity to acknowledge Dr. S.A.R.R. Palitha 
Dissanayake, Senior Lecturer in English, Department of Language Studies, Faculty of Indigenous Medical Sciences, Gampaha Wickramarachchi University of Indigenous Medicine, Yakkala, Sri Lanka for his kind help and guidance to finalize this research document.

Andalso, I would like to thanks Senior Assistant Librarian and other staff members of the Pandith G.P. Wickramarachchi Memorial Library of the Gampaha Wickramarachchi University of Indigenous Medicine, Yakkala, Sri Lanka for their corporation while searching literature data for this research work.

\section{Conflict of Interest: None}

\section{Source of Funding: None}

\section{Ethical Approval: Approved}

\section{REFERENCES}

1. Reid R, Robets F, Macduff E. Illustrated Pathology. $7^{\text {th }}$ ed. China: Churchill Living Stone Publication; 2011.

2. Rubin E, Gorsterin F, Rubin R, Schwarting R, Strayer D. Rubin's Pathology (Clinicopathologic foundation of Medicine). $3^{\text {rd }}$ ed. Lippincott Williams and Wilkins Publication; 2001.

3. Kumar P, Clark M. Kumar and Clark Clinical Medicine. $6^{\text {th }}$ ed. Philadelphia: Elsevier Limited; 2005.

4. Chaurasia BD. Human Anatomy. Volume 02. $4^{\text {th }}$ ed. New Delhi: CBS Publishers and Distributers; 2004.

5. Buddhadasa R. Charaka Samhita (Sinhala translation). $1^{\text {st }}$ ed. Colombo: Department of Educational Publication; 1960: 597600.

6. Buddhadasa R. Sushruta Samhita (Sinhala translation). $2^{\text {nd }}$ ed. Colombo: Department of Educational Publication; 2007: 282.

7. Buddhadasa R. Ashtanga Hridaya Samhita (Sinhala translation). $2^{\text {nd }}$ ed. Colombo: Department of Educational Publication; 2007: 289.

8. Murthy KRS. Madhava Nidana (roga vinischaya) of Madhavakara (English translation). $\quad 7^{\text {th }} \quad$ ed. $\quad$ Varanasi: Chaukhambha Orientalia; 2005: 26.

9. Buddhadasa R. Charaka Samhita (Sinhala translation). $1^{\text {st }}$ ed. Colombo: Department of Educational Publication; 1960: 597610.

10. Buddhadasa R. Sushruta Samhita (Sinhala translation). $2^{\text {nd }}$ ed. Colombo: Department of Educational Publication; 2007: 454460.

11. Buddhadasa R. Ashtanga Hridaya Samhita (Sinhala translation). $2^{\text {nd }}$ ed. Colombo: Department of Educational Publication; 2007: 411-424.

12. Perry KR. Hemorrhoids. [Internet]. 2019 [updated 2019 Sept. 24; cited 2021 May 21]. Available from https://emedicine.medscape.com.

13. Kumarasinghe A. Ayurveda Pharmacopoeia. Volume 01. Part 1. Colombo: Department Ayurveda; 2006: 154-155.

14. Nagodavithana P. Sharangadhara Samhita (Madhyakhanda) (Sinhala translation). $1^{\text {st }}$ ed. Colombo 10: Samayawardene Book Shop (Pvt) Ltd; 2001: 149.

15. Angadi RA. Text Book of Bhaishajya Kalpana Vijnana. Varanasi: Chaukhambha Subharati Prakashan; 2011.

16. Buddhadasa R. Charaka Samhita (Sinhala translation). $1^{\text {st }}$ ed. Colombo: Department of Educational Publication; 1960: 595596.

17. Buddhadasa R. Sushruta Samhita (Sinhala translation). $2^{\text {nd }}$ ed. Colombo: Department of Educational Publication; 2007: 281.

18. Buddhadasa R. Ashtanga Hridaya Samhita (Sinhala translation). $2^{\text {nd }}$ ed. Colombo: Department of Educational Publication; 2007: 286.

19. Murthy KRS. Madhava Nidana (roga vinischaya) of Madhavakara (English translation). $\quad 7^{\text {th }}$ ed. Varanasi: Chaukhambha Orientalia; 2005: 23.

20. Kulasekara BP. Medicinal Plants used in Ayurveda. Colombo: S. Godage and Brothers (Pvt) Ltd; 1998.

21. Warrier PK, Nambiar VPK, Ramankutty C. Indian Medicinal Plants. Volume 0105. Chennai: Orient Longman (Pvt) Ltd; 1994. 
Fernando BPA et.al. Evaluation of the efficacy of sapta winsati guggulu in the management of shushkarsha: a comparative clinical study.

22. Department of Ayurveda. Ayurveda Pharmacopoeia. Volume 01. Part 2. Colombo: Department of Educational Publication; 1994.

23. Hashempur MH, Khademi F, Rahmanifard M, Zarshenas MM. An Evidence-Based Study on Medicinal Plants for Hemorrhoids in Medieval Persia. Journal of Evidence-Based Complementary and Alternative Medicine. 2017: 1-3.

24. Singh P, Malhotra H. Terminalia chebula: A Review Pharmacognistic and Phytochemical Studies. International Journal of Recent Scientific Research. 2017; 8 (11): 21496-21507.
25. Yousefi M, Mahdavi MRV, Hosseini SM, Bahrami A, Davati A, Kamalinejad M, Faghihzadeh S. Clinical Evaluation of Commiphora Mukul, a Botanical resin, in the Management of Hemorrhoids: A randomized controlled trial. 2013; 9(36): 350-356.

How to cite this article: Fernando BPA, Hettiarachchi GTK, Kumara GUA et.al. Evaluation of the efficacy of sapta winsati guggulu in the management of shushkarsha: a comparative clinical study. Int J Health Sci Res. 2021; 11(6): 172-177. DOI: https://doi. org/10.52403/ijhsr.20210627 